\title{
Influence of Surface Properties Modified with Fine Shot Peening on Scuffing
}

\author{
Yuya Omiya', Masahiro Fujii' ${ }^{1}$, Ryo Ochiai', Koshi Ishimoto², Akihiro Ueda² \\ ${ }^{1}$ Graduate School of Natural Science and Technology, Okayama University, Okayama, Japan \\ ${ }^{2}$ Research Laboratory, Machine Elements Department, IHI Corporation, Yokohama, Japan \\ Email:omiya@okayama-u.ac.jp
}

How to cite this paper: Omiya, Y., Fujii, M., Ochiai, R., Ishimoto, K. and Ueda, A. (2018) Influence of Surface Properties Modified with Fine Shot Peening on Scuffing. Journal of Surface Engineered Materials and Advanced Technology, 8, 58-69. https://doi.org/10.4236/jsemat.2018.83006

Received: May 15, 2018

Accepted: July 15, 2018

Published: July 18, 2018

Copyright $\odot 2018$ by authors and Scientific Research Publishing Inc. This work is licensed under the Creative Commons Attribution International License (CC BY 4.0).

http://creativecommons.org/licenses/by/4.0/

\begin{abstract}
Recently, gears of high strength, reliability, and surface-damage-resistant under severe service conditions are required to achieve the weight saving and downsizing of a product. For the high-speed condition in particular, it is important to understand the influence of the surface properties on the scuffing resistance. If the effective surface profile to improve the lubrication property was found, the metal surfaces could be obtained with both surface strength and surface lubricity. Herein, the influence of surface properties modified with fine shot peening, which can form the arbitrary surface profile, on the scuffing resistance in the rolling-sliding contact machine element, was investigated. The scuffing test was performed using a two-cylinder rolling contact test machine. In a specific sliding, a faster roller of $60 \%$ and a sliding velocity of $1.75 \mathrm{~m} / \mathrm{s}$ were utilized. The scuffing test results with shot-peened test rollers and those with non-shot-peened test roller were compared. The influence of the surface roughness of the shot-peened test roller was also discussed. We found that the shot-peened roller had a better scuffing resistance compared with the roller without the shot-peening process.
\end{abstract}

\section{Keywords}

Contact Element, Scuffing, Shot Peening, Surface Properties, Surface Roughness, Micro Dimples

\section{Introduction}

To achieve the weight saving and downsizing of a product, the machine element especially of a contact element such as the gear is required to be of high strength, reliability, and surface-damage-resistant under severe service conditions. The breakage of an oil film between the metal interfaces easily occurs in such sever 
operational conditions. Thus, the scuffing at the metal interfaces occurs owing to the metal-to-metal contact with a large contact pressure [1] [2]. Some investigators have studied the influence of surface hardness, modification treatment, contact mechanism, and lubricants on the scuffing at the metal interfaces [3] [4] [5] [6]. They found that the proper surface roughness, the higher hardness, and the oil film are required to maintain the lubricant property between the metal interfaces. The surface profile would also be critical in preventing the scuffing occurrence. Thus, it is important to understand the influence of the surface profile on the scuffing resistance. The surface texture is well known as the surface profile modification parameter for low friction, less wear, and oil sump [7] [8] [9]. In addition, peening such as shot peening, cavitation peening, and laser peening can form the arbitrary surface profile with the changes in peening conditions to the metal surface. Furthermore, shot peening is well known as the reinforcement on the fatigue life to surface pressure and bending [10] [11]. When the effective surface profile is found to increase the lubrication property, the metal surface will be obtained with both surface strength and surface lubricity.

Herein, the influence of the surface profile with fine shot peening, which could form the arbitrary surface profile, on the scuffing resistance in the rolling-sliding contact machine element was investigated. The scuffing test was performed using a two-cylinder rolling contact test machine. The scuffing test results with shot-peened test rollers and those with non-shot-peened test rollers were compared. The influence of the surface roughness of the shot-peened test roller is also discussed. Turbine oil was used as the lubricating oil. Its density and viscosity index are $0.867 \mathrm{~g} / \mathrm{cm}^{3}$ and 106 , respectively. The specific sliding in the faster roller was chosen as $60 \%$. The sliding velocities were chosen as 1.75 $\mathrm{m} / \mathrm{s}$ in the scuffing test. The step load method was used in the scuffing test. The applied loading, running torque, friction coefficient, and temperature right below the interface using a K-type thermocouple were measured.

\section{Scuffing Test}

\subsection{Test Roller}

Figure 1 shows the shapes and dimensions of the test rollers. These rollers are called the faster roller and the slower roller. The outer diameter of the test rollers was $40 \mathrm{~mm}$. Their inner diameters and thicknesses were $23 \mathrm{~mm}$ and $10 \mathrm{~mm}$, respectively. The faster roller has a crowned shape. The crowning radius of the roller was $60 \mathrm{~mm}$. To measure the surface temperature at the contact point, the rollers were drilled for setting the thermocouples. The material of the test roller was bearing steel (JIS; SUJ2). The surface profiles of the rollers were modified using fine shot peening. These rollers are herein denoted as SP rollers. The surface roughness was varied by approximately 0.2 to 2.1 using shot peening. The test roller without shot peening was also conducted for comparison. These rollers are herein denotedas NP rollers. The surface roughness of the non-peened 


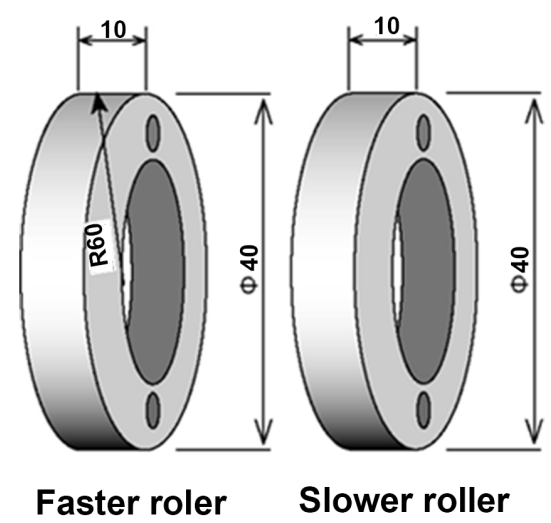

Figure 1. Shapes and dimensions of test rollers.

test roller was varied by approximately 0.1 to 1.0. Table 1 shows the surface properties of the test rollers. The test rollers with shot peening were SP1 to SP4. The test rollers without shot peening were NP5 to NP7. The surface roughness was described as the average values of the faster and slower rollers. The surface residual stress was measured using the polished surface of the fracture specimen. Table 2 shows the surface profile of the rollers in the axial and circumferential directions. The dependency in the surface profile of the test rollers with shot peening on the orientation was not shown. In the test rollers without shot peening, the grinding mark was shown in the axial direction.

\subsection{Test Equipment and Measurement Method}

Figure 2 shows the schematic of the scuffing test setup. The test equipment has two motors (faster motor and slower motor). The rotation speeds of the motors were controlled with the sliding velocity and specific sliding as test conditions. A contact load was applied using the tension bar. The tension load of the tension bar was measured using a load cell. The friction coefficient between the two rollers was calculated with the value measured using a torque detector on the shaft from the faster motor. The calculating equation is

$$
\mu=\frac{T}{r P}
$$

where $\mu$ is the friction coefficient, $T[\mathrm{~N} \cdot \mathrm{m}]$ is the measured shaft torque, $r[\mathrm{~m}]$ is the radius of faster roller, and $P[\mathrm{~N}]$ is the contact load. Table 3 shows the material properties of the lubricant oil in the scuffing test. The lubricant oil was consistently supplied to the contact area of the rollers. The temperature of the supplied lubricant oil was controlled at $40^{\circ} \mathrm{C}$. The amount of lubricant oil was $300 \mathrm{ml} / \mathrm{min}$. The temperatures on the surfaces of the rollers were measured using thermocouples attached to a point located $1 \mathrm{~mm}$ under the surface.

\subsection{Test Procedure and Test Condition}

The step loading method was chosen in the scuffing test. The specific sliding on the faster roller was $60 \%$. The sliding velocity was $1.75 \mathrm{~m} / \mathrm{s}$. The rotation speeds 
Table 1. Surface properties of the test rollers.

\begin{tabular}{ccccc}
\hline Test roller No & & SP1 & SP2 & SP3 \\
\hline Surface roughness, $\mu \mathrm{m}$ & $\mathrm{Ra}$ & 0.23 & 0.84 & 1.29 \\
Surface residual stress, $\mathrm{MPa}$ & $\mathrm{Rz}$ & 2.10 & 6.05 & 8.90 \\
\hline Test roller No & & -1307 & -1079 & -1178 \\
\hline Surface roughness, $\mu \mathrm{m}$ & $\mathrm{Ra}$ & 2.05 & 0.07 & NP6 \\
\hline Surface residual stress, MPa & $\mathrm{Rz}$ & 14.80 & 0.59 & 1.78 \\
\hline Test roller No & & -1047 & -1060 & -586 \\
\hline Surface roughness, $\mu \mathrm{m}$ & $\mathrm{Ra}$ & 1.10 & & \\
\hline & $\mathrm{Nz}$ & 4.26 & & \\
\hline & & -401 & & \\
\hline
\end{tabular}

Table 2. Surface roughness of test roller in axial and circumferential directions.

SP1

of the faster roller and slower roller were $1393 \mathrm{~m} / \mathrm{s}$ and $557 \mathrm{~m} / \mathrm{s}$, respectively. Table 4 shows the contact load at the contact point and the Hertzian contact stress at each step. The maximum number of load steps was 20 steps. The increment amount of the contact load was approximately $120 \mathrm{~N}$. The contact time of 


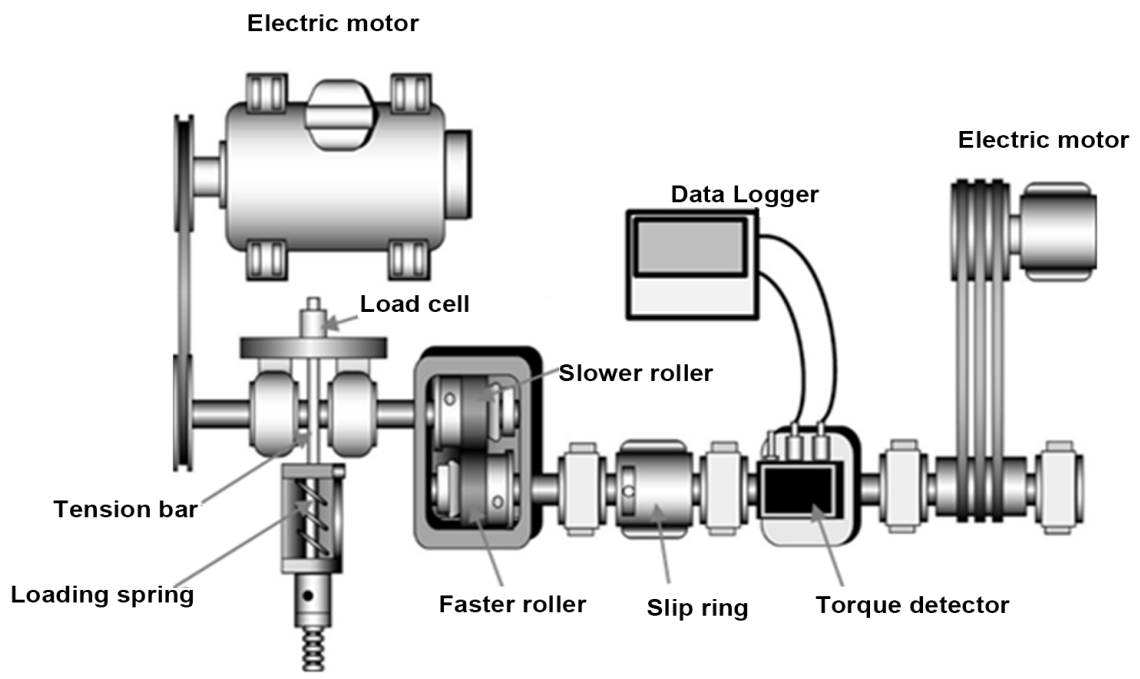

Figure 2. Schematic of scuffing test setup.

Table 3. Properties of lubrication oil.

\begin{tabular}{|c|c|c|}
\hline & & ISO VG32 Turbine oil \\
\hline \multicolumn{2}{|c|}{ Density at $288 \mathrm{~K}, \mathrm{~g} / \mathrm{cm}^{3}$} & 0.867 \\
\hline \multicolumn{2}{|c|}{ Flash point, $\mathrm{K}$} & 501 \\
\hline \multirow{2}{*}{ Viscosity $\mathrm{mm}^{2} / \mathrm{s}$} & $313 \mathrm{~K}$ & 32.6 \\
\hline & $373 \mathrm{~K}$ & 5.5 \\
\hline \multicolumn{2}{|c|}{ Viscosity index } & 106 \\
\hline
\end{tabular}

Table 4. Contact load and Hertzian contact stress.

\begin{tabular}{ccc}
\hline Number of load step & Contact load, N & Hertzian contact stress, MPa \\
\hline 1 & 553 & 1430 \\
2 & 670 & 1524 \\
3 & 789 & 1610 \\
$\downarrow$ & $\downarrow$ & $\downarrow$ \\
18 & 2874 & 2476 \\
19 & 3033 & 2521 \\
20 & 3194 & 2565 \\
\hline
\end{tabular}

each step was $600 \mathrm{~s}$. The scuffing was defined as the abrupt increase in temperature at the surface of the test rollers.

\section{Results and Discussion}

\subsection{Scuffing Load}

Figure 3 shows the relationship between scuffing load and average surface roughness. The ordinate is the scuffing load. The abscissa is the average surface roughness of the test rollers before a scuffing test. The arrows in Figure 3 show the scuffing did not occur in the test condition. The scuffing load was decreased 


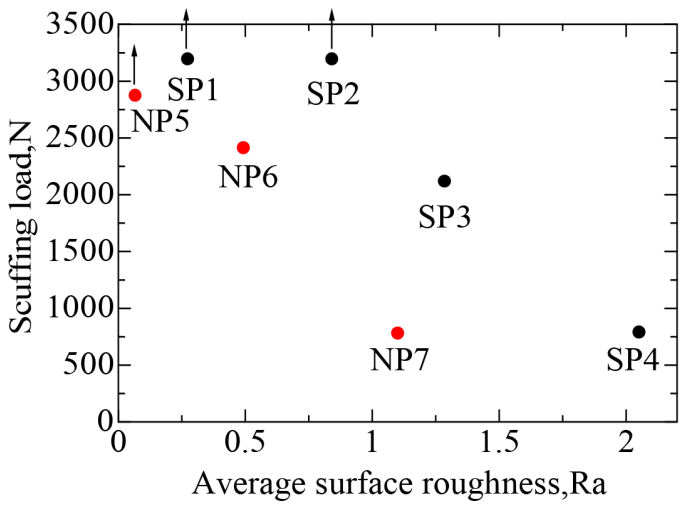

Figure 3. Results of relationship between scuffing load and average surface roughness.

as the average surface roughness was increased. A scuffing occurred easily when the surface roughness was larger. This tendency was shown from the result of the scuffing test with both types of rollers (SP and NP rollers). The result on the scuffing load was also evaluated using another parameter of roughness, i.e., $\mathrm{R}_{z}$, $\mathrm{R}_{\mathrm{pk}}$. However, the tendency was not shown. The results of the NP roller indicated smaller values than those of the SP roller. Thus, we found that the shot-peened surface profile has a scuffing resistance.

Figure 4 shows the relationship between scuffing temperature and average surface roughness of the test roller before the scuffing test. The ordinate is the scuffing temperature. The scuffing temperature in each test condition was plotted using the value immediately before the scuffing. The result indicated that the scuffing temperature was decreased as the surface roughness in the axial direction was increased. Further, the tendencies of the results were almost the same as those of the relationship between scuffing load and surface roughness.

Table 5 shows the surface roughness in the axial and circumferential direction of test rollers SP1, SP2, and NP5 in which scuffing did not occur. We observed that a convex area in the surface profile of test roller was worn and the concave area remained. To observe in more detail, the surfaces were observed using a laser microscope. Figure 5 and Figure 6 show the surface profiles of SP1 and NP5, respectively. (a) shows the initial surface. (b) shows the surface after the scuffing test. (c) shows the bird's eyes view of the surface after the scuffing test. In terms of the SP rollers, the surface worn in the convex area was observed. Nevertheless, the concave area remained the same. That the concave area remained is considered to behave like an oil reservoir. Meanwhile, the grinding marks on surface of NP5 dissolved due to wear. The difference between the convex area and concave area was not shown.

\subsection{Temperature and Friction Coefficient during the Scuffing Test}

Figures 7-10 show the changes in temperature at the surface and the friction coefficient during the scuffing test. The ordinates are the temperature and 


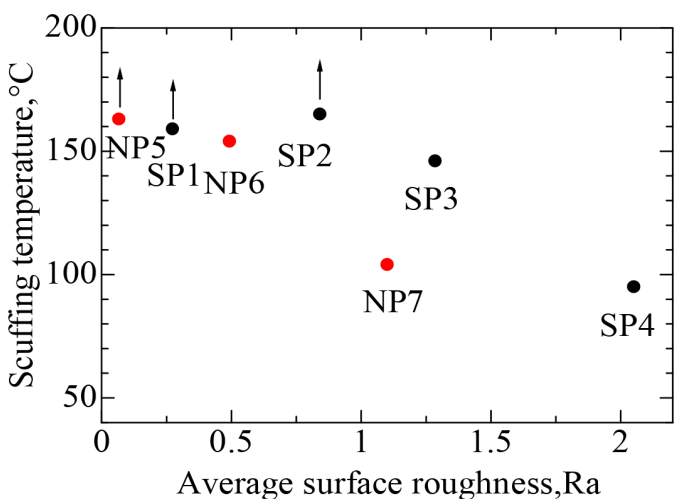

Figure 4. Results of relationship between scuffing temperature and average surface roughness.

Table 5. Surface roughness of test rollers SP1, SP2, and NP5.

Ax1 Circumferential direction

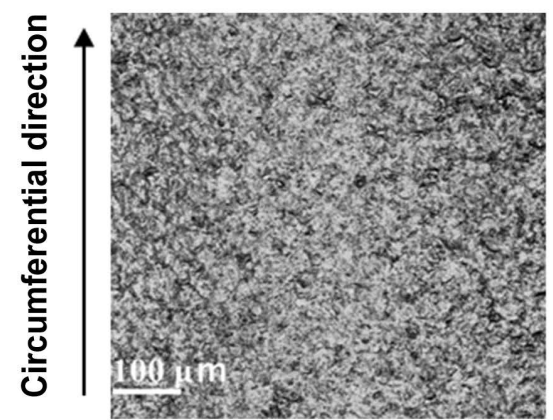

(a)

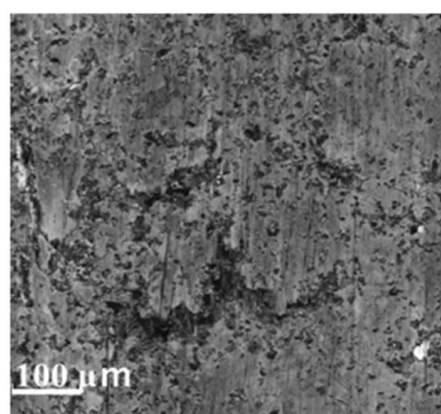

(b)

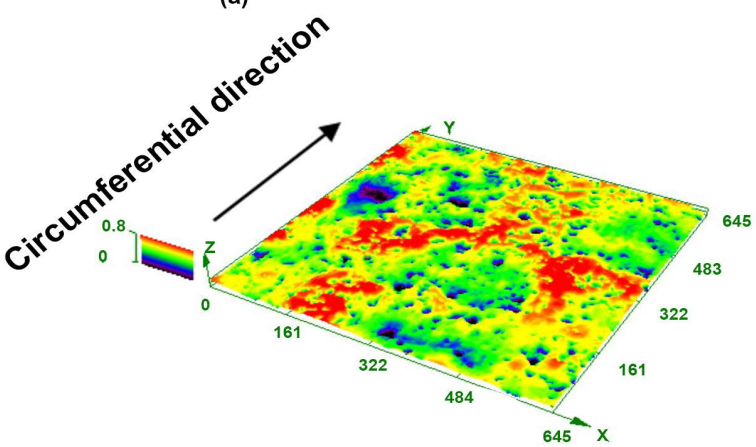

(c)

Figure 5. Surface profiles obtained using a laser microscope (a) SP1 before the scuffing test, (b) SP1 after the scuffing test, (c) SP1 after the scuffing test. 


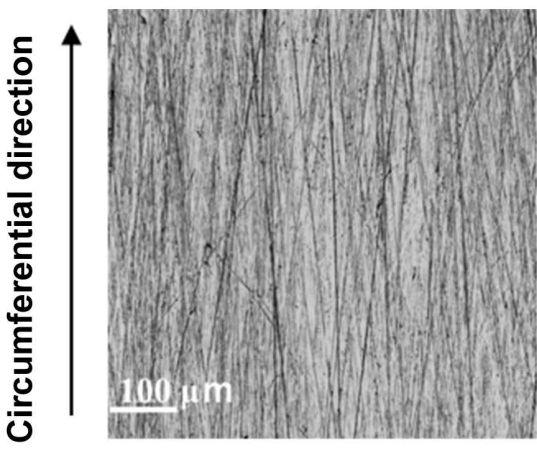

(a)

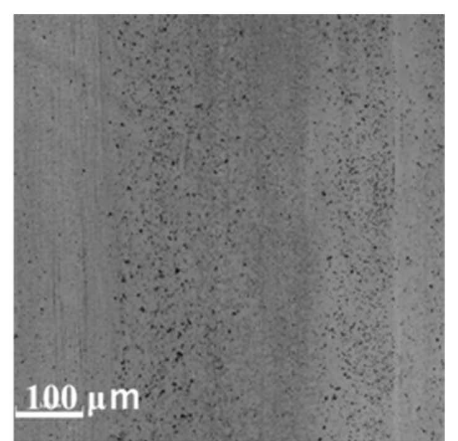

(b)

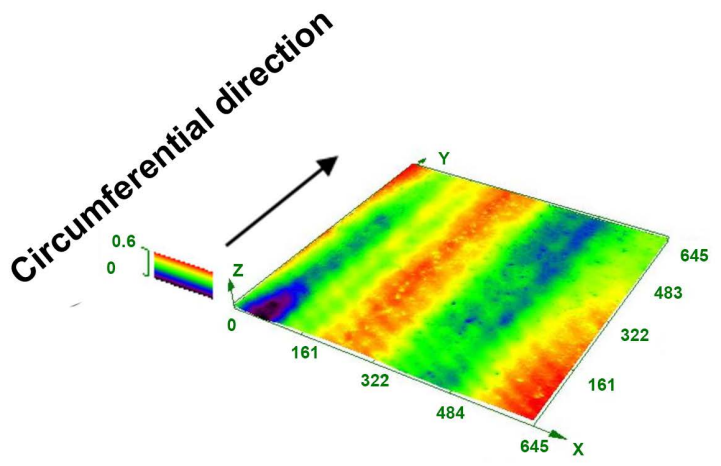

(c)

Figure 6. Surface profiles obtained using a laser microscope (a) NP5 before the scuffing test, (b) NP5 after the scuffing test, (c) NP5 after the scuffing test.

friction coefficient. The abscissa is the time of the scuffing test. The red line is the temperature on the surface of the faster roller. The black line is the temperature on the surface of the slower roller. Figure 7 shows the result of the scuffing test with roller SP2. Scuffing did not occur in this test condition. Regarding the behavior of the surface temperature, the temperature increased rapidly immediately after applying the contact load. However, the temperature on the surface became stable after approximately $600 \mathrm{~s}$. The temperature on the surface increased as the contact load was increased. Regarding the friction coefficient, a slightly large friction coefficient was observed in load steps 1 and 2 . The friction coefficient became stable with contact load after load step 2. The convex area on the test roller was worn in the early test step. The effectual surface for the scuffing was formed as shown in Figure 4. Figure 8 shows the result of the scuffing test with roller SP3. Scuffing occurred in load step 13 in this test. The significant difference between SP2 and SP3 regarding the temperature was not shown. However, when scuffing occurred, we observed that the temperature increased rapidly from the stable state with the contact load being constant. The friction coefficient during load steps 1, 2, and 3 decreased. An effectual surface was formed on test roller SP3 in these test steps. However, this surface did not prevent the scuffing. It was important to prevent the scuffing; as such, the effectual surface was formed in the early load step. Figure 9 shows the result of the 


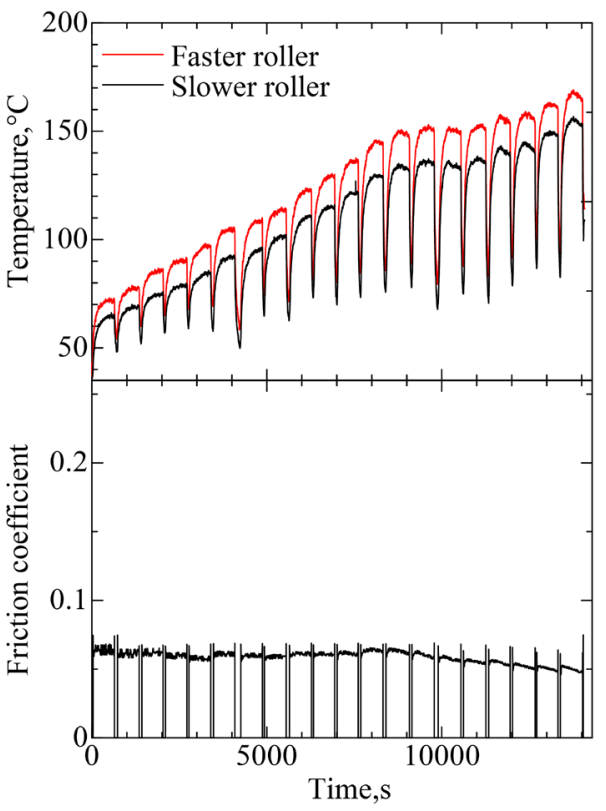

Figure 7. Changes in temperatures and friction coefficient during scuffing test (roller SP2).

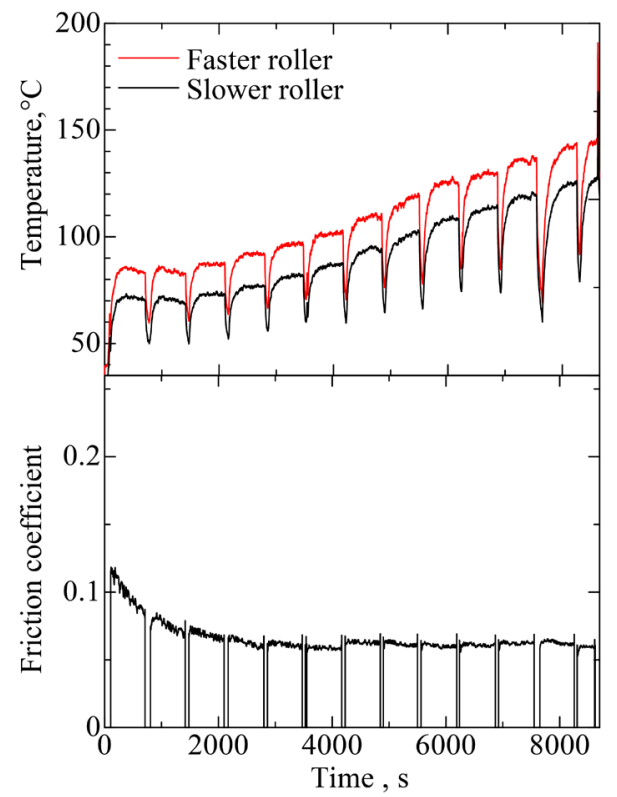

Figure 8. Changes in temperatures and friction coefficient during scuffing test (roller SP3).

scuffing test with roller NP5. Scuffing did not occur in this test. Initially, about the surface temperature was larger than that of the SP roller. This can be attributed to the larger contact area due to the smoother surface of NP5. The friction coefficient was observed as stable during the scuffing test. Thus, the effectual surface was formed on the surface. Figure 10 shows the result of the scuffing test with roller NP7. The scuffing occurred in load step 3 in this test. The temperature was also larger than that of the SP roller. Further, the friction coefficient 


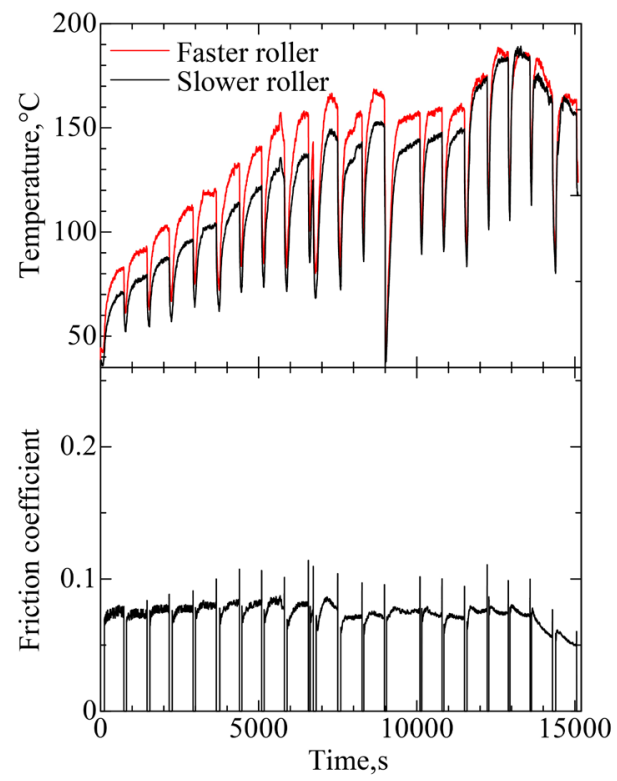

Figure 9. Changes in temperatures and friction coefficient during scuffing test (roller NP5).

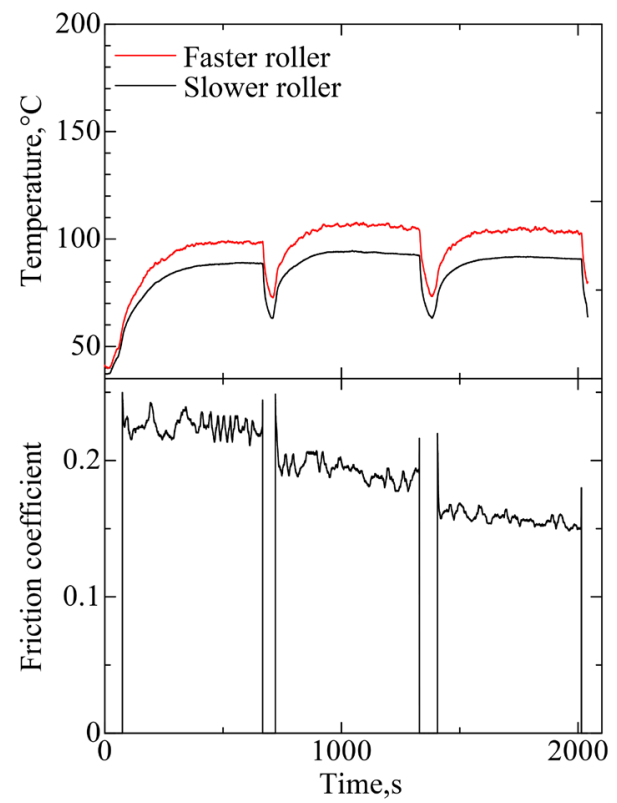

Figure 10. Changes in temperatures and friction coefficient during scuffing test (roller NP7).

during load steps 1,2, and 3 decreased. The scuffing occurred before the stable state and the effectual surface was not formed on the surface. According to Figure 4, approximately $160^{\circ} \mathrm{C}$ is the criterion of the oil film shortage on surfaces. The oil film on test rollers SP1 and SP2, in which scuffing did not occur, was held around $160^{\circ} \mathrm{C}$ because they had an effectual surface with the oil reservoir. The temperature on test roller NP5 was over $160^{\circ} \mathrm{C}$. An oxide layer is considered to have formed on the surface. 


\section{Conclusions}

Herein, the influence of a surface profile modified with fine shot peening on the scuffing resistance in a rolling-slipping contact machine element was investigated. The scuffing test using a two-cylinder rolling contact test machine was performed with test rollers processed with shot peening in the scuffing test. The obtained results are as follows:

1) The scuffing residence was improved as the surface roughness, $\mathrm{Ra}$ of the test roller was decreased. Scuffing occurred easily when the surface roughness was larger. Because it was important to prevent the scuffing, an effectual surface was formed in the early load step.

2) The fine shot peened roller had a better scuffing resistance compared with the roller without the shot-peening process.

3) Regarding the shot-peened roller, we found that a convex area, which was the asperities on the roller surface, was worn, and the concave area remained in the early load step. The concave area was thought to behave as an oil reservoir.

\section{Acknowledgements}

In this study, some test rollers from a shot-peen-processing company were provided. The authors thank the processing company, SINTOKOGIO, LTD.

\section{References}

[1] Iwai, R., Nonaka, T., Kubo, A. and Yabe, H. (1984) Fundamental on Scoring Failure (1st Report, Initiation and Progress of Scoring on Gear Teeth). Bulletin of JSME, 27, 823-830. https://doi.org/10.1299/jsme1958.27.823

[2] Enthoven, J. and Spikes, H. A. (1996) Infrared and Visual Study of the Mechanisms of Scuffing. Tribology Transactions, 39, 441-447. https://doi.org/10.1080/10402009608983550

[3] Yoshida, A., Fujii, M., Harano, T., Kimura, T., Shao, H. and Miura, K. (1998) Rolling Contact Fatigue and Scuffing of Surface Modified Rollers (in Case of Electroless Ni-P Alloy Plated Rollers and Sulfurized Rollers). Bulletin of JSME, Transaction of the JSME, Series C, 64, 1801-1807. https://doi.org/10.1299/kikaic.64.1801

[4] Miura, K., Komoda, T., Kuwata, T., Yoshida, A. and Fujii, M. (2001) Scuffing Characteristics of Wear Resisting Steel and Steel with Surface Modification Treatment. Journal of the JIME, 36, 225-231. https://doi.org/10.5988/jime.36.225

[5] Fujita, K., Obata F. and Koo, T. (1980) Study on the Scoring Resistance of Lubricating Oil in Two Cylinder Test: 2nd Report, Seizure Behavior under Pure Sliding Condition. Bulletin of JSME, Transaction of the JSME, Series C, 46, 953-961. https://doi.org/10.1299/jsme1958.24.729

[6] Fujita, K., Obata F. and Yamaura, I. (1981) Study on the Scoring Resistance of Lubricating Oil in Two Cylinder Test: 3rd Report, Seizure Behavior under Rolling-Sliding Contact Condition and the Relation between Seizure and Temperature of Base Oil. Bulletin of JSME, Transaction of the JSME, Series C, 47, 1518-1529. https://doi.org/10.1299/kikaic.47.1518

[7] Kumar, P.C., Menezes, P.L. and Kailas, S.V. (2008) Role of Surface Texture on Friction under Boundary Lubricated Conditions. Tribology Online, 3, 12-18 https://doi.org/10.2474/trol.3.12 
[8] Amanov, A., Pyun, Y.S., Zhang, B., Park, J.H. and Nohava, J. (2011) Preliminary Study of the Effect of Micro-Scale Dimple Size on Friction and Wear under Oil-Lubricated Sliding Contact. Tribology Online, 6, 284-290.

https://doi.org/10.2474/trol.6.284

[9] Nitta, I., Tsukiyama, Y., Nomura, S. and Takatsu, N. (2016) Frictional Characteristics of Clamp Surfaces of Aneurysm Clips Finished by Laser Processing. Journal of Advanced Mechanical Design, Systems, and Manufacturing, 10, JAMDSM0026.

https://doi.org/10.1299/jamdsm.2016jamdsm0026

[10] Seki, M., Yoshita, A., Ohue Y., Hongo, T., Kawamura, T. and Shimoyama, I. (2007) Influence of Shot Peening on surface Durability of Case-Hardened Steel Gears (Influences of Shot Velocity and Shot Diameter). Journal of Advanced Mechanical Design, Systems, and Manufacturing, 1, 518-529.

https://doi.org/10.1299/jamdsm.1.518

[11] Seki, M., Nishie, N., Kozai, S., Kakuda, M., Soyama, H., Naito, A. and Fujii, M. (2012) Fatigue Strength of Steel Rollers and Gears Treated by Cavitation Peening with Short Processing Time (a Case of Processing Time of $1 \mathrm{~min}$ and $5 \mathrm{~min}$ ). Journal of Advanced Mechanical Design, Systems and Manufacturing, 6, 33-43. https://doi.org/10.1299/jamdsm.6.33 